\title{
Development of Autologous Specific Reactivity to Human Neuroblastoma
}

\author{
KAZUO KAWAI, HIROYUKI SAKATOKU, TADASHI MATSUDA, KAZUYOSHI KAZUOKA, \\ SEIKO KUBO, HITOSHI KAMIYA, AND MINORU SAKURAI \\ Department of Pediatrics, Mie University School of Medicine, Edo-bashi, Tsu, Mie, Japan
}

\begin{abstract}
Antigenic analysis of neuroblastoma cells was performed by autologous typing and indirect immunofluorescent test combined with absorption tests. Serum of a patient with neuroblastoma before treatment showed weak reactivity with cultured autologous neuroblastoma cells, while serum obtained from the same patient 3 months after chemotherapy exhibited strong reactivity with the same indicator cells. This reactivity was absorbed with neither cultured autologous fibroblasts nor allogeneic tumor cells from seven neuroblastoma and two melanoma patients. In addition, cultured hematopoietic cells from two subjects, normal fetal and adult tissues also failed to remove the reactivity. This reactivity, however, was completely removed by the absorption with the cultured autologous neuroblastoma cells and the homogenate, suggesting that these neuroblastoma cells may express tumor specific antigen(s), located on neither normal cells in any stage of the development nor other malignant cells, although the cells and tissues we tested may not be adequate to confirm this. (Pediatr Res 20: 915-919, 1986)
\end{abstract}

\section{Abbreviations}

FBS, fetal bovine serum

PBS, phosphate buffered saline

FITC, fluorescein isothiocyanate

HMAg, heterologous membrane antigen

Neuroblastoma is a unique tumor with various biologic characteristics including a high incidence of spontaneous regression $(1,2)$ and the existence of neuroblastoma in situ (3), which lead to a general belief that neuroblastoma is immunogenic in man. After an initial report by Hellström et al. (4) in 1968, extensive investigations on immunologic aspects of neuroblastoma have been performed. But conclusive evidence for the presence of immune reactions directed to neuroblastoma-specific antigen(s) is lacking. Previously, we demonstrated that neuroblastoma cells express tumor-specific antigens as detected by the experiments examining the reactions between sera from the patients with neuroblastoma and allogeneic neuroblastoma cells (allogeneic combination) $(5,6)$. However, we were not able to rule out the possibility that the reactivity might not be tumor specific but some unknown alloantigens might be involved in the reaction observed. Recent investigations have also shown that most of the immunologic reactivities observed in the experiments using human tumor cells may not be directed to tumor-specific anti-

Received May 6, 1985; accepted May 7, 1986

Correspondence Dr. Kazuo Kawai, Department of Pediatrics, Mie University School of Medicine, 2-174 Edo-bashi, Tsu, Mie, 514, Japan.

This study was supported in a Grant-in-Aid for Cancer Investigation from the Ministry of Health and Welfare. gens, but to differentiation antigens. Recently, we established a neuroblastoma and an autologous fibroblast cell line from a patient (7). Herein, we report the detection of specific antibodies to neuroblastoma cell-associated antigens by the autologous typing.

\section{CASE REPORT}

On July 20, 1984 a 5-yr-old girl was admitted to our hospital because of a left abdominal mass and bilateral neck lymphadenopathies. She had been in excellent health until 3 wk before the admission when her mother noted the cervical swellings. The blood counts and biochemical blood analyses showed nothing abnormal except for a lactate dehydrogenase level of higher than $700 \mathrm{IU} / \mathrm{L}$. Radiographic examinations including computerized axial tomography revealed a left large suprarenal mass with diffuse finely stippled calcification and an anterior-mediastinal mass indicating the presence of metastatic lymph nodes. Complete skeletal surveys were negative. Bone marrow examination revealed the infiltration of tumor cells forming multiple clusters. The levels of urinary catecholamines and the derivatives were abnormally elevated (Dopamine $2000 \mu \mathrm{g} /$ day, VMA $43.7 \mathrm{mg} /$ day, HVA $192.8 \mathrm{mg} /$ day) (normal 190-740 $\mu \mathrm{g} /$ day, 4.7-11.4 $\mathrm{mg} /$ day, $1.3-6.6 \mathrm{mg} /$ day, respectively) and the diagnosis of stage IV neuroblastoma (8) was made.

Because of widespread metastases, intensive chemotherapy using cyclophosphamide $(10 \mathrm{mg} / \mathrm{kg} /$ day, days $1-5)$, epipodophyllotoxin (VM-26) $\left(50 \mathrm{mg} / \mathrm{m}^{2} /\right.$ day, days 1 and 2$)$, vincristine $\left(1.5 \mathrm{mg} / \mathrm{m}^{2}\right.$, day 3$)$, Cis platinum $\left(90 \mathrm{mg} / \mathrm{m}^{2}\right.$, day 3$)$, and doxorubicin $\left(30 \mathrm{mg} / \mathrm{m}^{2}\right.$, day 6$)$ was performed. The response to the chemotherapy was excellent and in 3 months, in October, 1984, CT scan revealed marked regression of the mediastinal mass and increased areas of calcification within the primary tumor. Approximately 7 months after the diagnosis she was relatively well on chemotherapy.

\section{MATERIALS AND METHODS}

Serum specimen (patient T.I.). Serum samples were sequentially obtained before treatment and after treatment from the patient T.I. described in the case report and were stored at $-70^{\circ}$ $\mathrm{C}$ until examination. In the present investigations we used a serum sample before treatment and serum obtained on October 27, 1984 after chemotherapy, and these sera were designated as "pretreatment serum" and "posttreatment serum," respectively. The levels of IgG in the samples were 1312 and $1372 \mathrm{mg} / \mathrm{dl}$, respectively.

Autologous cell lines. On July 20, 1984 cultures of bone marrow specimens obtained from the patient T.I. were started in the RPMI 1640 tissue culture medium supplemented with $15 \%$ FBS in plastic Falcon flasks. The flasks were washed after $24 \mathrm{~h}$ to remove floating cells. The cultures were maintained without medium change and in 23 days the growth of cells in 
monolayer has observed. These monolayer cells were composed of two morphologically different cell types; i.e. $\mathrm{Nb} / \mathrm{I}-\mathrm{M}$ and $\mathrm{Fb} /$ $\mathrm{I}-\mathrm{M}$. $\mathrm{Nb} / \mathrm{I}-\mathrm{M}$ cells were easily isolated by gentle mechanical scraping and maintained in the same medium. They were subsequently transferred to different flasks at irregular intervals whenever the cultures became confluent. The cells after 20-22 splittings were in this study. On the other hand, Fb/I-M cells were detouched from the flasks with $0.1 \%$ trypsin and $0.01 \%$ EDTA in PBS, and subsequently maintained in Eagle's minimal essential medium after a rinse in PBS. Fb/I-M cells thus obtained were transferred to other flasks at intervals of approximately 1 month, and the cells obtained after five to six splittings were used in this study. As described in detail in our previous studies (7) these cells were confirmed to consist of neuroblastoma and normal fibroblast cells, respectively, as shown by the electron microscopic observation. Briefly, the $\mathrm{Nb} / \mathrm{I}-\mathrm{M}$ cells show neuroblast-like morphology and evidently synthesize and store catecholamines. Cytogenetic studies indicated that the cell line contained chromosomal abnormalities including $14 \mathrm{q}$ deletion.

Tissue culture. Neuroblastoma and other cell lines used in this study except NKS have been described previously (9-16). NKS was established from a patient with neuroblastoma at St. Jude Children's Research Hospital. These cell lines except IMR-32 were obtained from Dr. Y. Komada, Division of Pathology, St. Jude Children's Research Hospital, and IMR-32 resistered at American Type Culture Collection was obtained from Japan Flow Laboratories Inc. Neuroblastoma and hematopoietic cell lines were cultured in RPMI 1640 tissue culture medium supplemented with $10 \%$ FBS. Melanoma cell lines were maintained in Eagle's minimal essential medium.

Lyophilized tissue powders. First trimester human fetal tissue and nonneoplastic human various tissues of preterm infants and adults were obtained at therapeutic abortion and autopsy, respectively. These tissues were minced with scissors in PBS and sonicated by ultrasonic disruptor (Tomy Seiko Co., Tokyo, Japan) at $4^{\circ} \mathrm{C}$ for $10 \mathrm{~min}$. The sonicates were washed three times with PBS, to which 4 volumes of acetone were added. The suspensions were lyophilized by a Labconco lyophilizer (Labconco Corp., Kansas City, MO).

Immunofluorescent tests. Indicator cells $(\mathrm{Nb} / \mathrm{I}-\mathrm{M})$ were harvested by mechanical scraping, suspended in complete medium, and plated on $12 \times 32 \mathrm{~mm}$ coverslips in $15 \times 35 \mathrm{~mm}$ glass culture flasks. Cells were then incubated at $37^{\circ} \mathrm{C}$ in a humidified atmosphere of $5 \% \mathrm{CO}_{2}$ for a few days. For immunofluorescent staining, the coverslips were taken out of the culture flasks, and then washed free of medium. The adherent cells were fixed in 95\% ethanol in PBS for $5 \mathrm{~min}$ and allowed to dry, and then drops of test sera were added. The coverslips were incubated at $37^{\circ} \mathrm{C}$ for $30 \mathrm{~min}$ in a moist chamber.

After the incubation, the cells were washed three times in PBS, and drops of FITC-conjugated goat antihuman IgG F $\left(\mathrm{ab}^{\prime}\right)_{2}$ (Cappel Laboratories Inc., West Chester, PA) in a 1:20 dilution were added. The coverslips were incubated at $37^{\circ} \mathrm{C}$ for additional 20 $\mathrm{min}$. After the incubation, the coverslips were washed three times in PBS, and then mounted with $50 \%$ glycerine in PBS. The cells were examined for specific reactions by a fluorescence microscope (Olympus, Tokyo, Japan). Each specimen was accompanied by a control specimen which was handled in parallel to exclude nonspecific reactions.

Serum absorption. Cultured fibroblasts, a neuroblastoma (NCG) and two melanoma (SK-MEL-37, SK-MEL-40) cell lines were harvested with $0.1 \%$ trypsin and $0.01 \%$ EDTA in PBS. Other neuroblastoma (Nb/I-M, NKP, NKS, NJF, SK-N-SH, $\mathrm{Nb}-1, \mathrm{IMR}-32$ ) cell lines were harvested by mechanical scraping, and two hematopoietic cell lines (NALM-1, HPB-ALL) were collected by simple aspiration. These cells were rinsed three times with PBS before absorption. As a qualitative test evaluating the effects of the absorption (qualitative absorption test), the homogenate of cultured autologous $\mathrm{Nb} / \mathrm{I}-\mathrm{M}$ cells, tissue powder or cells were mixed with an equal volume of serum. By the way, the cell counts of the cell pellets were varied from $1.0 \times 10^{8}-6.6 \times 10^{8} /$ $\mathrm{ml}$. As a quantitative test evaluating the effects of the absorption (quantitative absoption test), cells were incubated with serum in varying from $1 \times 10^{5}-1 \times 10^{9}$ cells $/ \mathrm{ml}$. The incubation for the absorption was carried out at room temperature for $120 \mathrm{~min}$ with continuous gentle agitation. The cells used for absorption were then separated from the serum by centrifugation at 2,000 $\mathrm{rpm}$ for $5 \mathrm{~min}$ after the incubation.

\section{RESULTS}

Immunofluorescent tests for autologous neuroblastoma cells. In contrast to the weak reaction for pretreatment crude serum (immunofluorescent titer $=1: 2$ ), the posttreatment crude serum obtained from the same patient (T.I.) reacted strongly with the autologous neuroblastoma cells $(\mathrm{Nb} / \mathrm{I}-\mathrm{M})$ used as indicator cells. The immunofluorescent titer for the latter was 1:32. Figure 1 shows positive cell membrane and cytoplasmic fluorescence observed when posttreatment serum was tested against the cultured neuroblastoma cells. After these sera were mixed in equal volumes, the immunofluorescent titer was also examined. The reactivity was as strong as in the posttreatment serum alone.

Absorption analysis. Absorption analysis was performed using posttreatment sera. Autologous fibroblasts, allogeneic neuroblastoma, melanoma and hematopoietic cells, and whole fetal (1st trimester) tissue, and the brain, liver, renal and adrenal tissues of both preterm infants (24-26th wk of gestation) and adults failed to absorb the reactivity, while the reactivity was completely by the indicator cells or the homogenate, as shown by the qualitative absorption tests. When a quantitative test was performed to determine the lowest number of the cells necessary to remove completely the specific reactivity against the indicator cells in the indirect immunofluorescent test, $1 \times 10^{8}$ cells $/ \mathrm{ml}$ serum were required as shown in Figures 2-3).

Specificity of the reactions. Specificity of the reactions was tested by several experiments in which the primary (posttreatment serum) or the secondary [FITC-conjugated goat antihuman $\mathrm{IgG} \mathrm{F}\left(\mathrm{ab}^{\prime}\right)_{2}$ ] antibody or both were omitted. In none of these experiments the indicator cells were stained showing that the staining was derived from neither autofluorescence nor nonspecific binding of the FITC-labeled antibodies. After the posttreatment sera were mixed with the same volume of FBS, this mixture was also examined for reactivity. The addition of FBS did not decrease the reactivity. When a quantitative absorption test was also performed with the cultured autologous neuroblastoma cells harvested by tripsinization, no decrease in the absorbability was seen.

\section{DISCUSSION}

There are some major problems in resolving whether immunological factors play any role in the pathological process in human neuroblastoma. The most important questions to be resolved are whether neuroblastoma-specific antigens exist and whether the immunological system of the patients with these tumors recognize the antigens during the course of their diseases. Since Foley (17) first reported in 1953, the evidence for tumorspecific antigen(s) as detected in experimental systems has been accumulating (18). However, tumor-specific antigen(s) have not been found universally in human neoplastic cells. Certainly, unlike in inbred animal systems, the specificity of an immune reaction to human tumor cells borne by genetically different hosts is extremely difficult to analyze. Old and coworkers (16, $19,20)$ investigated cell surface antigens of human malignant melanoma, and demonstrated the presence of melanoma-specific antigens. They used a serological method referred to as autologous typing. This method has some advantages in that it eliminates the effects of alloantibodies to blood group antigens and histocompatibility antigens and that it detects antigens expressed by autologous tumor cells but none of the others. We also 


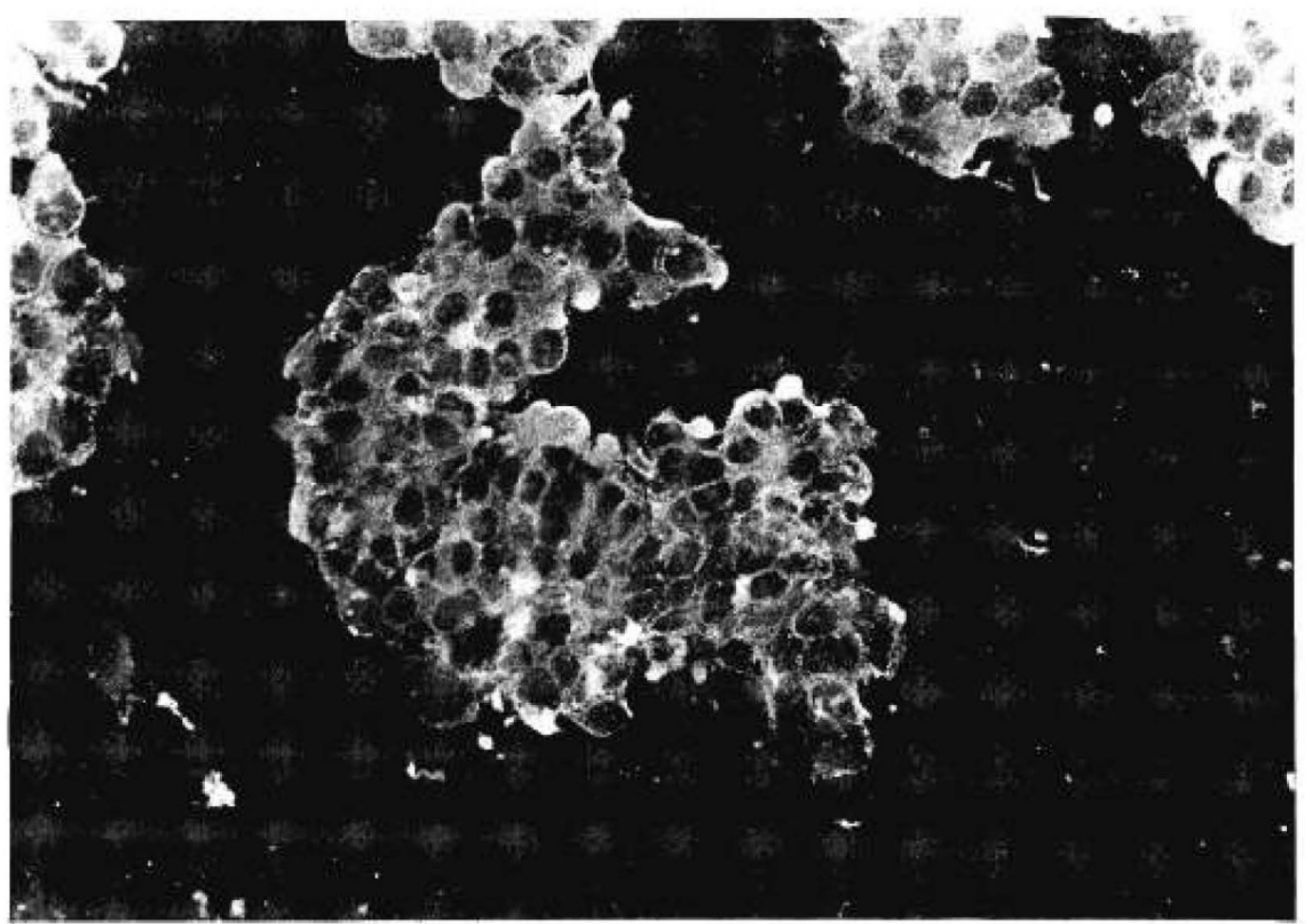

Fig. 1. Cultured neuroblastoma cells (Nb/I-M) were stained with 1:4 diluted autologous posttreatment serum patient (T.I.). Cell membrane and cytoplasmic fluorescence is observed $(\times 200)$.

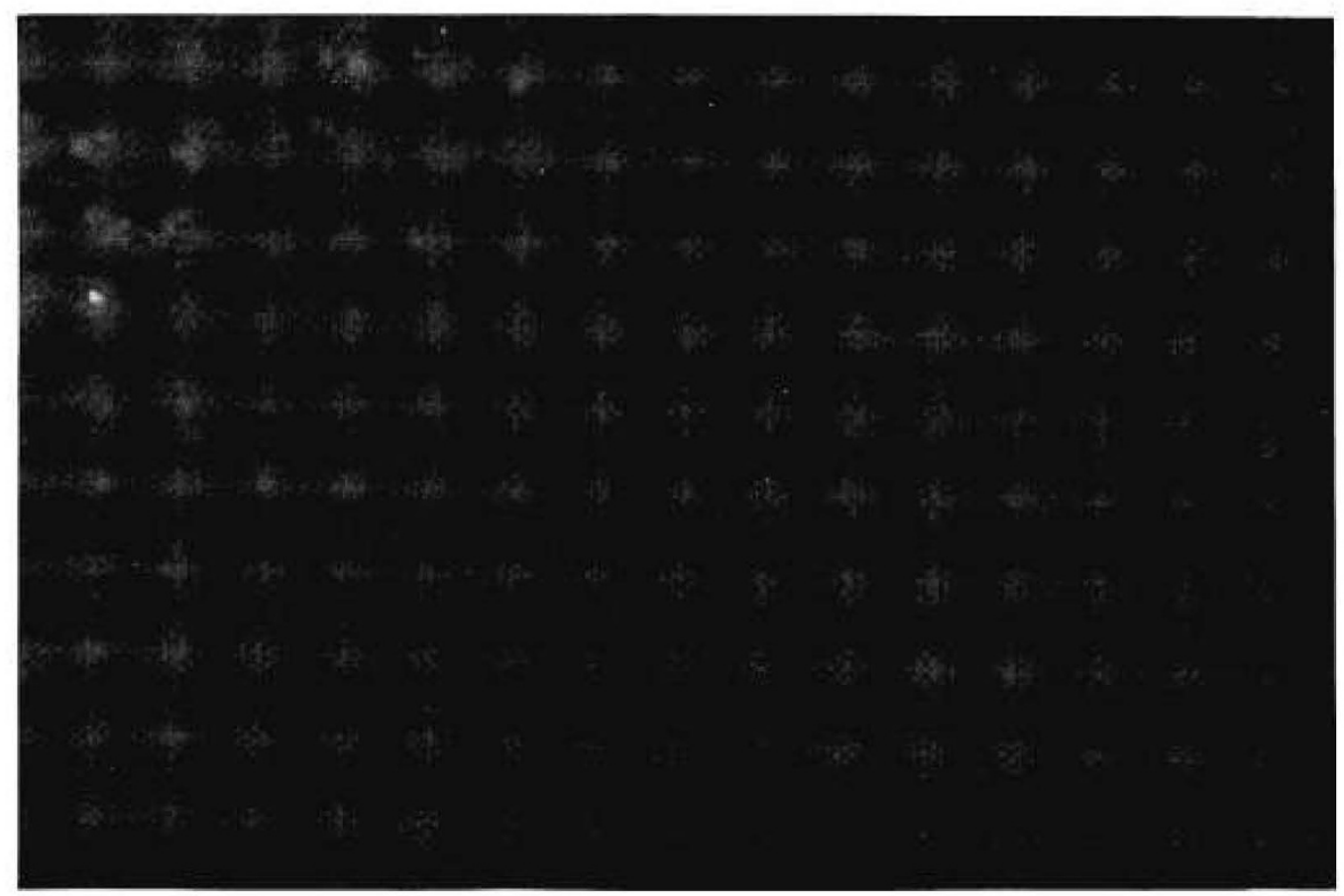

Fig. 2. Cultured neuroblastoma cells $(\mathrm{Nb} / \mathrm{I}-\mathrm{M})$ were not stained with the autologous posttreatment serum absorbed with $1 \times 10^{8} \mathrm{Nb} / \mathrm{I}-\mathrm{M}$ cells/ $\mathrm{ml}(\times 200)$.

performed antigenic analyses of neuroblastoma cells by autologous typing. Thus, we detected antibodies in autologous sera directed to the tumor cells as indicated by an indirect immunofluorescent test combined with absorption tests.

Serum of a patient with neuroblastoma before treatment showed weak reactivity with cultured autologous neuroblastoma cells, while serum obtained from the same patient 3 months after chemotherapy exhibited strong reactivity with the same indicator cells. Then, absorption analyses were performed in order to determine the specificity of the reactivity. Various cells and tissues were used for the absorption tests. Absorbers used in this experiment included (a) autologous fibroblasts, (b) allogeneic tumor cells from seven neuroblastoma, two melanoma, and two lymphoid leukemia patients, (c) 1st trimester whole fetal tissues, and (d) brain, renal, and adrenal tissues from both preterm infants and adults as well as (e) cells and the homogenate from a cultured autologous neuroblastoma. It was demonstrated that this reactivity was absorbable with none of the samples listed above, except autologous neuroblastoma cells and the homogenate. 


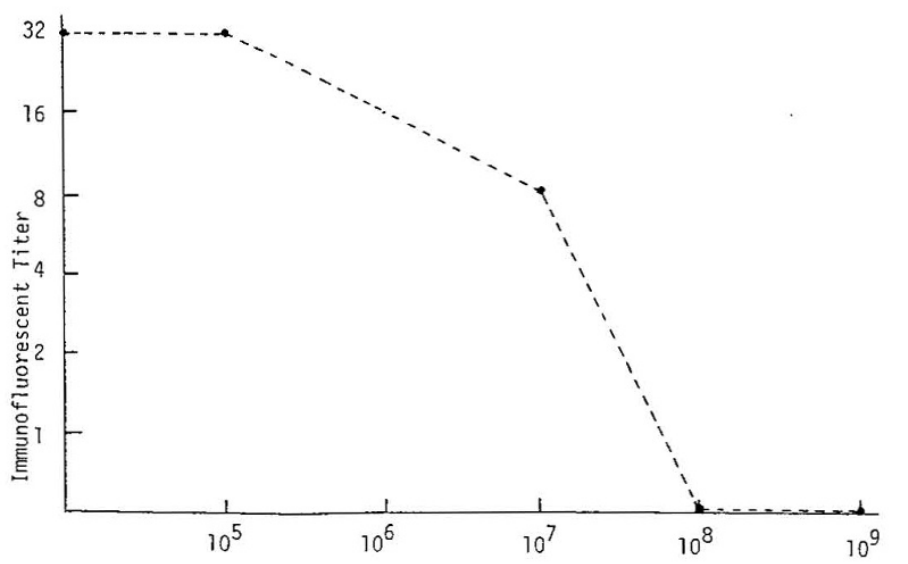

Number of Absorbing Cells per Milliliter Serum

Fig. 3. Quantitative test evaluating the effects of absorption. Ordinate shows immunofluorescent titer of posttreatment serum from neuroblastoma patient T.I. tested against cultured autologous neuroblastoma cells $(\mathrm{Nb} / \mathrm{I}-\mathrm{M})$. Sera were absorbed with varying numbers of cells ranging $1 \times 10^{8}$ to $1 \times 10^{9}$ cells $/ \mathrm{ml}$ for $120 \mathrm{~min}$ at room temperature.

Irie et al. $(21,22)$ described that human cells in tissue culture acquired a new membrane antigen designated as "HMAg." They reported that HMAg originated from fetal calf serum used in the tissue culture and was reactable to natural antibody in human serum. Therefore, they concluded that the presence of tumorspecific antigen on cultured tumor cells could be demonstrated only after excluding the possibility of HMAg. However, in our experiments, none of these absorbers but autologous neuroblastoma cells was able to absorb the reactivity, clarifying that the reactivity is not related to HMAg. Because most absorbers used in this experiment should also have HMAg. In addition, we mixed the posttreatment sera with the same volume of FCS, and then examined this mixture as to the reactivity. The addition of FCS did not decrease the reactivity indicating that the reactivity does not seem to be directed to FCS.

It is also known that cultured cells derived from some types of human tumors possess $\mathrm{Fc}$ or $\mathrm{C} 3 \mathrm{~b}$ receptors $(23,24)$. The possibility that the reactivity observed in our experiments might be related to the $\mathrm{Fc}$ or $\mathrm{C} 3 \mathrm{~b}$ bindings is unlikely. Thus, the difference in the reactivity between pretreatment and posttreatment sera was large, while neither the grade of aggregate formation of $\mathrm{IgG}$ nor the level of IgG seems to be different between them.

We considered the possibility that trypsinization may remove glycopeptides from the surfaces of various cells, as indicated by Glick et al. (25). In fact, trypsinization was performed only in a few cases as described. Furthermore, when a quantitative absorption test was performed with the cultured autologous neuroblastoma cells harvested by trypsinization, no decrease in the absorbability of the reactivity was seen.

The data we obtained suggest that the neuroblastoma may express class 1 antigen(s) as designated by Old (20), which denote antigens that are expressed on autologous tumor cells but none of the normal autologous cells nor on any type of normal or malignant allogeneic cells. However, we have to keep in mind a possibility that the antibodies we detected may react with antigens that exist in some of normal and tumor cells but none of the cells or tissues we tested.

Jose and coworkers $(26,27)$ also demonstrated specific antibodies and antigen using a radioimmunoelectrophoretic technique, although their characteristics were not always analyzed in detail. However, they also suggested that these antibodies may bind to the antigen specifically and exist as immune complexes in the circulation. They postulated that these complexes might play a role in the escape mechanisms from specific cellular immune destruction. The mixture containing pretreatment and posttreatment sera showed the reactivity in between and the levels of IgG were not different between these two sera. Therefore, the reactivity does not seem to be due to immune complexes. Although the specific antibody titer appeared to have increased as tumor size decreased, we are merely able to suggest that patients with neuroblastoma might recognize specific antigens under "certain" conditions. The roles of these specific antibodies remain to be elucidated.

Currently, monoclonal antibodies directed to the antigens present on human neuroblastoma cells have been used for immunodiagnosis and therapy (28-32). These antibodies are also potentially useful for antigenic analyses of neuroblastoma cells. However, neuroblastoma-specific monoclonal antibodies have not been obtained.

Acknowledgments. The authors thank Dr. Naoyuki Kamatani, Associate Professor of Institute of Rheumatology Tokyo Women's Medical College, for useful discussion.

\section{REFERENCES}

1. Everson TC, Cole WH 1966 Spontaneous regression of cancer. WB Saunders Co, Philadelphia

2. Gross RE, Farber S, Martin LW 1959 Neuroblastoma sympatheticum: a study and report of 217 cases. Pediatrics 23:1179-1185

3. Beckwith JB, Perrin EV 1963 In situ neuroblastoma: a contribution to the natural history of neural crest tumors. Am J Pathol 43:1089-1104

4. Hellström IE, Hellstrom KE, Pierce GE, Alexander AH 1968 Demonstration of cell-bound and humoral immunity against neuroblastoma cells. Proc Natl Acad Sci USA 60:1231-1238

5. Kawai K, Kazuoka K, Kamiya H, Sakurai M, Izawa T, Suzuki H 1979 Chemoimmunotherapy against neuroblastoma. J Jap Soc Cancer Ther $14: 757$

6. Kazuoka K, Matsuda T, Kawai K, Kamiya H, Sakurai M 1982 Immunology and immunotherapy of neuroblastoma and Wilms' tumor. Jap J Pediatr Med 14:1117-1123

7. Kawai K, Sakatoku H, Kamiya T, Kamiya H, Sakurai M, Kaneko Y 1985 Establishment and characterization of a human neuroblastoma cell line $(\mathrm{Nb} /$ I-M). Mie Med J 35:191-197

8. Evans AE, D'Angio GJ, Randolph J 1971 A proposed staging for children with neuroblastoma. Cancer 27:374-378

9. Biedler JL, Helson L, Spengler BA 1973 Morphology and growth, tumorigenicity, and cytogenetics of human neuroblastoma cells in continuous culture. Cancer Res 32:2643-2652

10. Brodeur GM, Green AA, Hayes FA, Williams KJ, Williams DL, Tsiatis AA 1981 Cytogenetic features of human neuroblastoma and cell lines. Cancer Res 41:4678-4686

11. Carey TE, Takahashi T, Resnick LA, Oettgen HF, Old LJ 1976 Cell surface antigens of human malignant melanoma: mixed hemadsorption assays for humoral immunity to cultured autologous melanoma cells. Proc Natl Acad Sci USA 73:3278-3282

12. Minowada J, Tsubota T, Greaves MF, Walters TR 1977 A non-T, non-B human leukemia associated antigens. J Natl Cancer Inst 59:83-87

13. Minowada J, Koshiba H, Kuronishi I, Lok S, Taysumi F, Han Y, Srivastava BIS, Ohnuma T 1981 Marker profiiles of human leukemia and lymphoma cell cell lines. J Cancer Res Clin Oncol 101:91-100

14. Miyake S, Shimo Y, Kitamura T, Nojyo Y, Nakamura T, Imasyuku S, Abe T 1973 Characteristics of continuous and functional cell line NB-1, derived from a human neuroblastoma. Jiritsu-shinkei 10:115-120

15. Shiku H, Takahashi T, Resnick LA, Oettgen HF, Old LJ 1977 Cell surface antigens of human malignant melanoma III. recognition of autoantibodies with unusual characteristics. J Exp Med 145:784-789

16. Tumilowicz JJ, Nichols WW, Cholon JJ, Grecne AE 1970 Definition of a continuous human cell line derived from neuroblastoma. Cancer Res 30:2110-2118

17. Foley EJ 1953 Antigenic properties of methylchoranthrene-induced tumors in mice of the strain of origin. Cancer Res 13:835-837

18. Klein J, Sjogren HO, Klein E, Hellstrom KE 1960 Demonstration of resistance against methylcholanthrene induced sarcomas in the primary autochthonous host. Cancer Res 20:1561-1572

19. Shiku H, Takahashi T, Oettgen HF, Old LJ 1976 Cell surface antigen of human malignant melanoma. II. Serological typing with immune adherence assays and definition of two new surface antigens. J Exp Med 144:873-881

20. Old LJ 1981 Cancer immunology: the search for specificity. Cancer Res 41:361-375

21. Irie RF, Irie K, Morton DL 1974 Natural antibody in human serum to a neoantigen in human cultured cells grown in fetal bovine serum. J. Natl Cancer Inst 52:1051-1058

22. Irie RF, Irie K, Morton DL 1974 Characteristics of heterologous membrane antigen on cultured human cells. J. Natl Cancer Inst 53:1545-1551 
23. Preud'homme JL, Gonnot M, Fellows M, Seligman M 1979 Receptors for Ig $M$ on human lymphoblastoid B and T cell lines. Scand J Immunol 10:207212

24. Stein PC, Rand N, Char DH. 1981 Fc and C3b receptors on cultured retinoblastma cells. Invest Ophthalmol Vis Sci 21:550-553

25. Glick MC, Schlesinger H, Hummeler 1976 Glycopeptides from the surface of human neuroblastoma cells. Cancer Res 36:4520-4524

26. Jose DG, Skvaril F 1974 Serum inhibitors of cellular immunity in human neuroblastoma. Ig G subclass of blocking activity. Int J Cancer 13:173-178

27. Jose DG, Seshadri R 1974 Circulating immune complexes in human neuroblastoma: direct assay and role in blocking specific cellular immunity. Int $\mathrm{J}$ Cancer 13:824-838

28. Kemshed JT, Treleaven JG, Gibson FM, Ugeistad J, Rembaum A, Philip T 1985 Monoclonal antibodies and magnetic microspheres used for the depletion of malignant cells from bone marrow. In: Evans AE, D'Angio GJ, Seeger RC (eds) Advances in Neuroblastoma Research. Alan R. Liss, New York, pp 413-424

29. Seeger RC, Reynolds CP, Vo DD, Ugelstad J, Wells J 1985 Depletion of neuroblastoma cells from bone marrow with monoclonal and magnetic immunobeads. In: Evans AE, D'Angio GJ, Seeger RC (ed) Advances in Neuroblastoma Research. Alan R. Liss, New York, pp 443-458

30. Donner L, Triche TJ, Israel MA, Seeger RC, Reynolds CP 1985 A panel of monoclonal antibodies which discriminate neuroblastoma from Ewing's sarcoma, rhabdomyosarcoma, neuroepithelioma, and hematopoietic malignancies. In: Evans AE, D'Angio GJ, Seeger RC (eds) Advances in Neuroblastoma Research. Alan R. Liss, New York, pp 347-366

31. Franz CN, Duerst RE, Ryan DH, Gelsomino NL, Constine LS, Gregory PK 1985 Antineuroblastoma monoclonal antibodies which do not bind to bone marrow cells. In: Evans AE, D'Angio GJ, Seeger RC (eds) Advances in Neuroblastoma Research. Alan R. Liss, New York, pp 485-500

32. Cheung NKV, Saarinen U, Neely J, Miraldi F, Strandjord S, Warkentin P, Coccia P 1985 Development of neuroblastoma monoclonal antibodies for potential utilization in diagnosis and therapy. In: Evans AE, D'Angio GJ, Seeger RC (eds) Advances in Neuroblastoma Research. Alan R. Liss, New York, pp 501-506 